\title{
In vitro Efficacy of Emblica officinalis Against MRSA Isolated from Buffaloes Suffering from Subclinical Mastitis
}

\author{
Ramnayan Yadav ${ }^{1}$, Jitendra Pratap Singh ${ }^{1}$, Satyavrat Singh ${ }^{1}$, Ramakant $^{1 *}$, \\ Naveen Kumar Singh ${ }^{2}$ and Vibha Yadav ${ }^{3}$ \\ ${ }^{1}$ Department of Veterinary Medicine, C.V.Sc. E A.H., A.N. D. U. A. E T. Kumarganj, Ayodhya, U.P. INDIA \\ ${ }^{2}$ Department of Veterinary Clinical Complex, C.V.Sc. \& A.H., A.N. D. U. A. E T. Kumarganj, Ayodhya, U.P. INDIA \\ ${ }^{3}$ Department of Veterinary Microbiology, C.V.Sc. \& A.H., A.N. D. U. A. E T. Kumarganj, Ayodhya, U.P. INDIA
}

*Corresponding author: Ramakant; E-mail: ramakant.dr2@gmail.com

Received: 18 Jan., 2020

Revised: 14 March, 2020

Accepted: 21 March, 2020

\begin{abstract}
The present study describes in- vitro efficacy of Emblica officinalis against Methicillin Resistant S. aureus mastitis. Diffusion technique was used to assess in-vitro efficacy of Emblica officinalis. Zone of inhibition was measured and used to compare the in-vitro efficacy. The zone ranged between 10-13 mm with maximum zone of $13 \mathrm{~mm}$ observed in $200 \mathrm{and} 225 \mathrm{mg} / \mathrm{ml}$ DMSO disc, followed by $12 \mathrm{~mm}$ in 175 and $150 \mathrm{mg} / \mathrm{ml}$ DMSO disc, $11 \mathrm{~mm}$ in $125 \mathrm{mg} / \mathrm{ml}$ DMSO disc and $10 \mathrm{~mm}$ in $100 \mathrm{mg} / \mathrm{ml}$ DMSO disc. The results indicate that the sensitivity pattern for Emblica officinalis at $200 \& 175 \mathrm{mg} / \mathrm{ml} \mathrm{DMSO}$ concentration and was comparable with the standard antibiotics in Methicillin sensitive S. aureus. In Methicillin resistant S. aureus isolates, the zone of inhibition was in the order Oxytetracycline $(15 \mathrm{~mm})$ followed by Emblica officinalis $-200(13 \mathrm{~mm})$ and Methicillin, ampicillin, gentamicin, ofloxacin were resistance.
\end{abstract}

Keywords: Emblica officinalis, Methicillin Resistant Staphylococcus aureus, Buffaloes, Subclinical Mastitis

Subclinical mastitis is mostly characterized by no visible changes in appearance of milk and udder, but decrease milk production by 10 to 20 percent with undesirable effect on its constituent and nutritional value rendering it of low quality and unfit for processing. The sub clinical mastitis (SCM) is indeed a more serious and responsible for much greater loss to the dairy industry (Kader et al., 2002). Sub clinical mastitis (SCM) is a herd problem, acts as a repository of microorganisms that leads to the spread of infection to the other animals undetectable to naked eyes. Mastitis has diverse etiological factors like bacteria, virus, fungus, physical, chemical, toxins and other environmental factors etc. About 90 percent of pathogens responsible for udder inflammations are environmental pathogens (Lassa and Smulski, 2013). In sub clinical mastitis the Staphylococcus aureus is the key organism throughout the world. Staphylococcus aureus has gained the antibiotic resistance against several drugs in the recent past. The indiscriminate use of antibiotics like Ampicillin, Penicillin, Oxacillin and Methicillin may contribute to the increasing occurrence of antibiotic resistant strains in animals with mastitis. Resistance of $S$. aureus to antimicrobial agents can complicate treatment of its infections (Lowy, 2003). Among S. aureus, MethicillinResistant Strains (MRSA) has recently emerged as a serious life-threatening infective agent which does not respond to a lot of antimicrobial treatments (Kamal et al., 2013).

In this scenario alternative herbal therapy holds importance. Plants produce wide array of bioactive molecules, most of which probably evolved as chemical defense against predation or infection (Samie et al., 2010). Limited studies have been conducted to explore the efficacy of Emblica officinalis against mastitogens. E. officinalis or Phyllanthus

How to cite this article: Yadav, R., Singh, J.P., Singh, S., Ramakant, Singh, N.K. and Yadav, V. (2020). In vitro efficacy of Emblica officinalis against MRSA isolated from buffaloes suffering from subclinical mastitis. J. Anim. Res., 10(2): 281-289. 
emblica (Syn: Amla, Indian Gooseberry) is an evergreen tree which is highly prized in tropical Asia. Emblica officinalis (E.O.) has been rightly named as the king of all medicinal crops. Apart from traditional uses, there are several reports in the pharmacological actions of E.O. based on modern scientific investigations, especially antiinflammatory action (Madhuri et al., 2011). Antimicrobial action (Rajeshkumar et al., 2001), anti-oxidant action (Akhtar et al., 2011).

\section{MATERIALS AND METHODS}

\section{Selection of animal and collection of milk sample}

The study was conducted at Ayodhya and Amethi districts of U.P. Samples were collected from lactating buffaloes with the history of reduced in milk yield but no visible physical abnormality in udder and changes in milk. On the basis of stratified random sampling. Two blocks were selected from each districts followed by two villages from each block and twenty five samples were collected from each village. A thorough examination of udder will be performed for the detection of any abnormality in the udder like the presence of any lesion, heat, pain and swelling. Milk from each quarter will withdraw for detecting the abnormality in the milk like colour and consistency. Such examination was continued until final selection of those buffaloes, which revealed sub clinical signs.

The milk samples (about $10 \mathrm{ml}$ ) was collected after washing the udder and teat with antiseptic solution (potassium permanganate) and thoroughly wiping with dry clean cloth in a sterile container from each quarter after discarding first 2 to 3 milking stream. The samples were brought in ice pack for bacteriological examinations.

\section{Screening of milk sample for sub clinical mastitis}

Battery of tests namely White side test (Fig. 1) and California mastitis test were used to detect sub clinical mastitis in buffaloes and those samples that showing strong positive reaction were selected for isolation of $S$. aureus. The CMT is performed to detect the presence of sub clinical infections. White side test and somatic cell count were performed using slandered procedures as described by (Schalm et al. 1971).

\section{Sample Preparation}

Milk samples was incubated in sterile nutrient broth at $37^{\circ} \mathrm{C}$ for $24 \mathrm{hrs}$ to check growth of bacteria; and then grown bacteria were streaked on mannitol salt agar (MSA) plate and incubated in incubator, the grown bacterial colony was tested for Gram's staining. Gram positive bacteria were transferred to nutrient agar slant and biochemical test namely (Catalase, Nitrate reduction test, Coagulase, IMViC etc) were performed followed by Beta- Hemolysis in Blood agar.

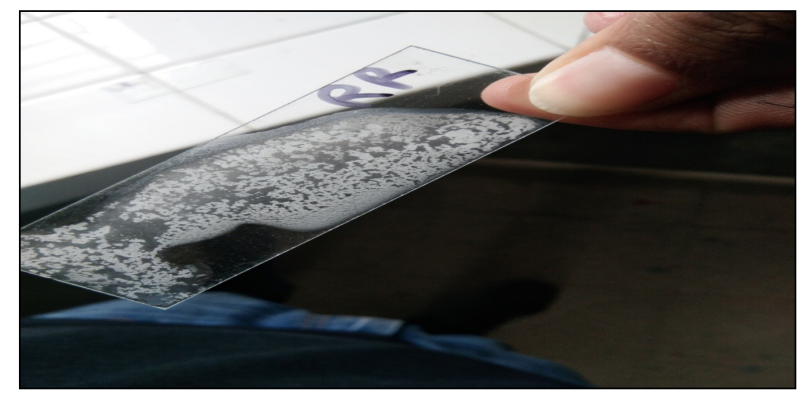

Fig. 1: Reaction of milk to White side test

\section{Identification of $S$. aureus}

Identification of $S$. aureus was carried out according to (Talan et al., 1989), where each sample of milk was directly inoculated into mannitol salt agar (MSA) and incubated at $37^{\circ} \mathrm{C}$ for $24 \mathrm{hrs}$ (Fig. 2). Mannitol fermented colony from primary cultures were purified by subculture into nutrient agar slants and incubated at $37^{\circ} \mathrm{C}$ for 24 48 hour and stored at $4^{\circ} \mathrm{C}$ until further use. Gram stain slides were investigated (Fig. 3) according to Barrow and Felltham, 2003. For biochemical characterization of $S$. aureus, Methyl Red test, Voges-Proskaur test, Catalase test, Slide and Tube coagulase test, Nitrate reduction test and haemolysis on blood agar were performed.

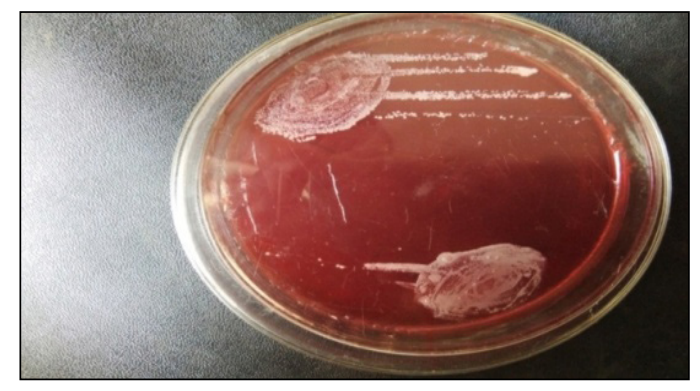

Fig. 2: S. aureus colony on mannitol salt agar 


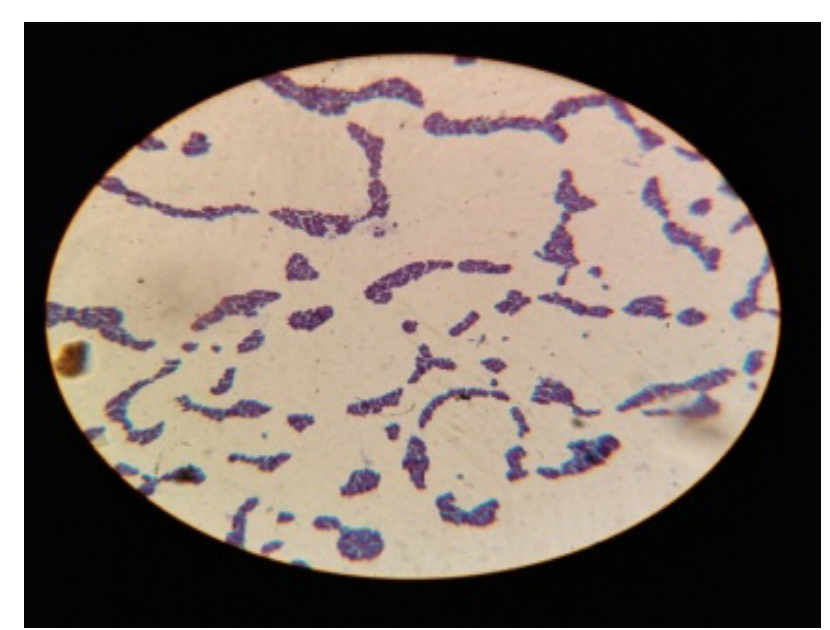

Fig. 3: S. aureus in characteristic arrangement "bunch of grapes" in gram staining

\section{Collection of Emblica officinalis fruit and processing}

Emblica officinalis fruit were collected from local market, deseeded, dried in shed and then powdered. The powder was soaked in ethanol solvent for 48 hour and processed by soxhlet extractor for extraction of E.O. fruit. It was finally filtered by Whatman Filter Paper No. 1 for a clear solution of Emblica officinalis fruit powder. Filtrate was concentrated in incubator at $45^{\circ} \mathrm{C}$ to obtain the final extract. The extract was stored under $4^{\circ} \mathrm{C}$ until the preparation of E. O. discs. Lastly the prepared disc of Emblica officinalis will be soaked in different concentration of Dimethyl Sulphoxide (DMSO) and Antibiotic sensitivity test (ABST) was carried out with comparing antibiotic disc.

\section{Disc preparation}

A stock solution of E.O. extracts was prepared by dissolving $25 \mathrm{mg}, 50 \mathrm{mg}, 75 \mathrm{mg}, 100 \mathrm{mg}, 125 \mathrm{mg}, 150$ $\mathrm{mg}, 175 \mathrm{mg}, 200 \mathrm{mg}$, and $225 \mathrm{mg}$ of extract with one $\mathrm{ml}$ of their respective solvents (sterile distilled water and 99.9 percent dimethyl sulfoxide) was mixed and finally make the $25 \mathrm{mg} / \mathrm{ml}, 50 \mathrm{mg} / \mathrm{ml}, 75 \mathrm{mg} / \mathrm{ml}, 100 \mathrm{mg} / \mathrm{ml}, 125 \mathrm{mg} /$ $\mathrm{ml}, 150 \mathrm{mg} / \mathrm{ml}, 175 \mathrm{mg} / \mathrm{ml}, 200 \mathrm{mg} / \mathrm{ml}, 225 \mathrm{mg} / \mathrm{ml}$ have then used to impregnate in sterilized blank discs who were cut with the help of commercial punch machine (Bauer et al., 1996). Distilled water and dimethyl sulfoxideloaded discs were used as negative controls for aqueous and ethanolic extracts respectively. All impregnated discs were ensured to be fully dried in $45^{\circ} \mathrm{C}$ in incubator for 18 to 24 hour prior to the application on bacterial lawn. The standard antibiotic disc used as positive controls for all $S$. aureus strains.

\section{Antimicrobial susceptibility procedure}

\section{Disk diffusion test}

The bacterial inoculums was uniformly spread using sterile cotton swab on a sterile petri dish. The antibiotic disks were placed on top of the previously inoculated nutrient agar medium surface with the help of sterile forceps. Each disc must press down to ensure complete contact with the agar surface. The plates were incubated for 18-24 hrs at $37^{\circ} \mathrm{C}$ temperature in bacteriological incubator before an interpretation of the result. If the organisms were killed or inhibited by the concentration of the antibiotic, there will be no growth in the immediate area around the discs represented as zone of growth inhibition. The diameter of the zone of inhibition is directly proportional to the sensibility of the isolate and to the diffusion rate of antibiotics through the agar medium. A zone of inhibition was measured in millimeters. The result of the test can be interpreted by using the criteria published by Clinical and Laboratory Standard Institute (CLSI formerly the National Committee for the Clinical Laboratory Standard or NCCLS, (2009). The list of selected antibiotic is given in table 1 .

Table 1: Codes and concentration of selected antibiotic discs

\begin{tabular}{llll}
\hline $\begin{array}{l}\text { Sl. } \\
\text { No. }\end{array}$ & Name of \\
antibiotic disc & $\begin{array}{l}\text { Code of } \\
\text { disc }\end{array}$ & Concentration of disc \\
\hline 1 & Ampicillin & $\mathrm{A}$ & $10 \mathrm{mcg} / \mathrm{disc}$ \\
2 & Cephotaxim & $\mathrm{Ce}$ & $30 \mathrm{mcg} / \mathrm{disc}$ \\
3 & Cloxacillin & $\mathrm{Cx}$ & $1 \mathrm{mcg} / \mathrm{disc}$ \\
4 & Erythromycin & $\mathrm{E}$ & $15 \mathrm{mcg} / \mathrm{disc}$ \\
5 & Gentamicin & Gen & $50 \mathrm{mcg} / \mathrm{disc}$ \\
6 & Methicillin & MET & $5 \mathrm{mcg} / \mathrm{disc}$ \\
7 & Ofloxacin & Of & $2 \mathrm{mcg} / \mathrm{disc}$ \\
8 & Oxytetracycline & O & $30 \mathrm{mcg} / \mathrm{disc}$ \\
9 & Streptomycin & $\mathrm{S}$ & $10 \mathrm{mcg} / \mathrm{disc}$ \\
& & & $25 \mathrm{mg} / \mathrm{disc}, 50 \mathrm{mg} / \mathrm{disc}, 75 \mathrm{mg} /$ \\
10 & Amla discs & EO & disc, $100 \mathrm{mg} / \mathrm{disc}, 125 \mathrm{mg} / \mathrm{disc}$, \\
& & & $150 \mathrm{mg} / \mathrm{disc}, 175 \mathrm{mg} / \mathrm{disc}, 200$ \\
& & & $\mathrm{mg} / \mathrm{disc}, 225 \mathrm{mg} / \mathrm{disc}$ \\
11 & Oxacillin strip & Oxa & $0.016-256 \mathrm{mcg} / \mathrm{ml}$ \\
\hline
\end{tabular}




\section{Enzyme oxacillin strip test}

It is a unique MIC determination paper strip which is coated with two different antibiotics on a single strip in a concentration gradient manner. The upper half has oxacillin with a highest concentration tapering downwards and capable of showing MIC in the range of 0.064-8.0 $\mathrm{mcg} / \mathrm{ml}$, whereas lower half is similarly coated with vancomycin concentration gradient in reverse direction to give MIC in the range of $0.19-16.0 \mathrm{mcg} / \mathrm{ml}$.

\section{RESULTS AND DISCUSSION}

Total 200 buffaloes were screened for sub clinical mastitis out of which 115 (57.5 percent) animal were found positive for sub clinical mastitis. These 115 samples from subclinically positive buffaloes were subjected to cultural examination for detection of $S$. aureus. Out of 115 samples, 102 samples ( 88.70 percent) were found positive for $S$. aureus. Antibiotic resistance pattern of isolates of $S$. aureus were studies against following commonly used antibiotics.

Table 2: Zone of inhibition at different concentration of Emblica officinalis discs

\begin{tabular}{|c|c|c|}
\hline \multirow{2}{*}{$\begin{array}{l}\begin{array}{l}\text { Concentration } \\
\text { (mg/ml DMSO) }\end{array} \\
\text { EO-100 }\end{array}$} & \multicolumn{2}{|c|}{ Zone of inhibition (percent isolates) } \\
\hline & $\begin{array}{l}11 \mathrm{~mm}(20 \text { per } 10 \mathrm{~mm} \text { (80 per } \\
\text { cent })\end{array}$ & \\
\hline EO-125 & $\begin{array}{ll}11 \mathrm{~mm}(85 \text { per } & 10 \mathrm{~mm}(15 \text { per } \\
\text { cent }) & \text { cent })\end{array}$ & \\
\hline EO-150 & $\begin{array}{l}12 \mathrm{~mm}(90 \text { per } 11 \mathrm{~mm}(10 \text { per } \\
\text { cent })\end{array}$ & \\
\hline EO-175 & $\begin{array}{l}13 \mathrm{~mm}(10 \text { per } 12 \mathrm{~mm} \text { (80 per } \\
\text { cent }) \\
\text { cent })\end{array}$ & $\begin{array}{l}11 \mathrm{~mm}(10 \\
\text { per cent })\end{array}$ \\
\hline EO-200 & $\begin{array}{l}13 \mathrm{~mm}(90 \text { per } 11 \mathrm{~mm}(10 \text { per } \\
\text { cent }) \\
\text { cent })\end{array}$ & \\
\hline EO-225 & $\begin{array}{ll}13 \mathrm{~mm}(80 \text { per } & 12 \mathrm{~mm}(10 \text { per } \\
\text { cent }) & \text { cent })\end{array}$ & $\begin{array}{l}11 \mathrm{~mm}(10 \\
\text { per cent })\end{array}$ \\
\hline
\end{tabular}

\section{In-vitro efficacy of Emblica officinalis}

Diffusion technique was used to assess in vitro efficacy of Emblica Officinalis. In vitro efficacy of disc prepared from ethanolic extract of E.O. at different concentrations 100 $\mathrm{mg} / \mathrm{ml}$ DMSO (EO-100), $125 \mathrm{mg} / \mathrm{ml}$ DMSO (EO-125), $150 \mathrm{mg} / \mathrm{ml}$ DMSO (EO-150), $175 \mathrm{mg} / \mathrm{ml}$ DMSO (EO-
175), $200 \mathrm{mg} / \mathrm{ml}$ DMSO (EO-200) and $225 \mathrm{mg} / \mathrm{ml} \mathrm{DMS}$ (EO-225) were studied against 20 isolates of $S$. aureus. Zone of inhibition was measured and used to compare the in vitro efficacy. The zone ranged between $10-13 \mathrm{~mm}$ with maximum zone of $13 \mathrm{~mm}$ observed in 200 and $225 \mathrm{mg} / \mathrm{ml}$ DMSO disc, followed by $12 \mathrm{~mm}$ in 175 and $150 \mathrm{mg} / \mathrm{ml}$ DMSO disc, $11 \mathrm{~mm}$ in $125 \mathrm{mg} / \mathrm{ml}$ DMSO disc and $10 \mathrm{~mm}$ in $100 \mathrm{mg} / \mathrm{ml} \mathrm{DMSO}$ disc. The details are given in table 2 .

\section{Comparison of Emblica officinalis and antibiotic discs}

As maximum sensitivity was recorded against oxytetracycline antibiotic disc, it was taken as standard disc to compare the in-vitro efficacy of disc prepared from ethanolic extract of E.O. at $175 \mathrm{mg} / \mathrm{ml} \mathrm{DMSO}$ and 200 $\mathrm{mg} / \mathrm{ml}$ DMSO concentration. The zone of inhibition was in decreasing order as Oxytetracycline $(13 \mathrm{~mm})$ followed by Methicillin (11 mm), E.O.-200 (11 mm), EO-175 (10 $\mathrm{mm})$, Erythromycin $(10 \mathrm{~mm})$, Ampicillin and Cloxacillin (resistant).The antibiotic resistance pattern given in Fig. 4.

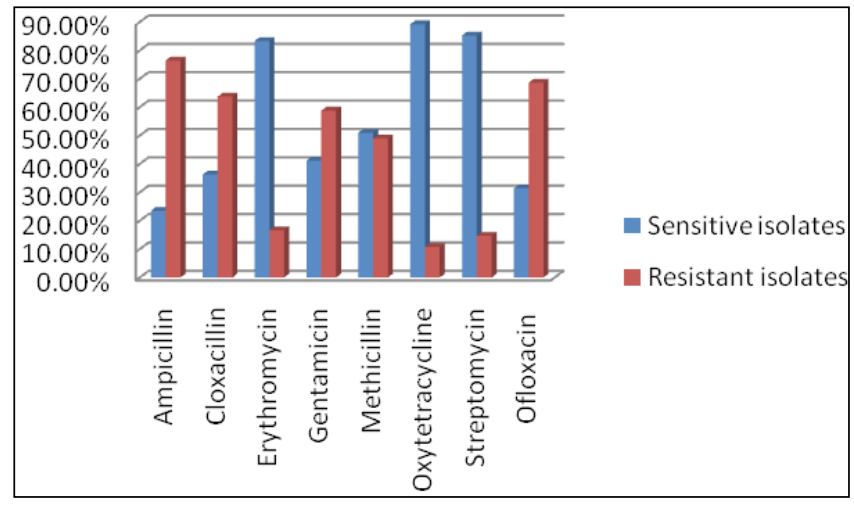

Fig. 4: Graphical representation of antibiotic resistance pattern

The results indicate that the sensitivity pattern for E.O. at 200 and $175 \mathrm{mg} / \mathrm{ml}$ DMSO concentration was comparable with the standard antibiotics in Methicillin sensitive $S$. aureus. In Methicillin Resistant S. aureus isolates, the zone of inhibition was in the order Oxytetracycline (15 $\mathrm{mm}$ ) followed by EO-200 (13 $\mathrm{mm})$, and Methicillin, Ampicillin, Gentamicin, Ofloxacin, E.O. 50 are resistance (Fig. 5).

Methicillin resistance has been earlier reported from this region by (Ankita and Nimali, 2015; Yadav et al., 2017). Yadav et al. (2017) reported Methicillin resistance in 18.58 percent animals. The isolation of MRSA has been 
reported from mastitic milk from various parts of world including India (Asrat et al., 2013). However earlier study by (Chandrashekhran et al., 2015) had reported 5.11 percent MRSA in cows. The details of MIC Range of $S$. aureus are given in Fig. 6. and 7.

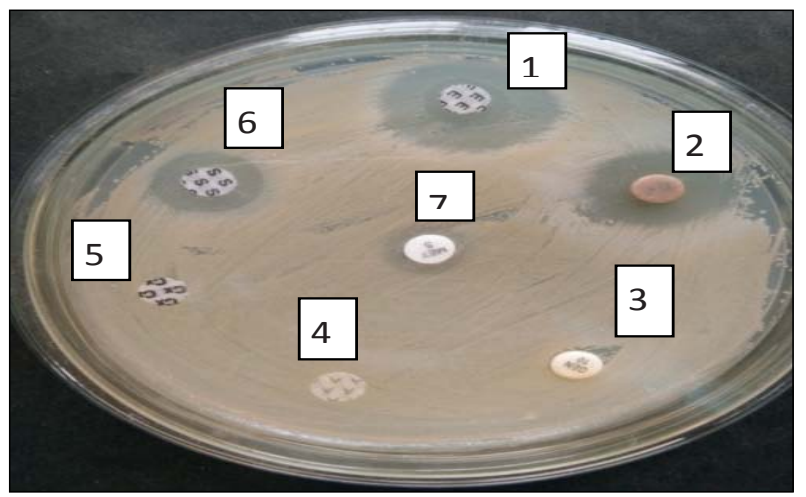

(1) Erythromycin disc (2) Amla Disc (3) Gentamicin disc (4) Ampicillin disc (5) Cloxacillin disc (6) Streptomycin disc (7) Methicillin disc

Fig. 5: Antibiotic resistance pattern of different antibiotics against isolates of $S$. aureus
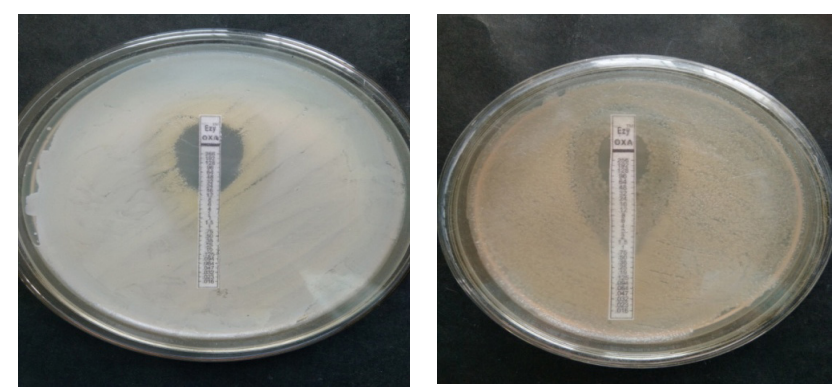

Fig. 6: MIC of S. aureus by Ezy OXA strip

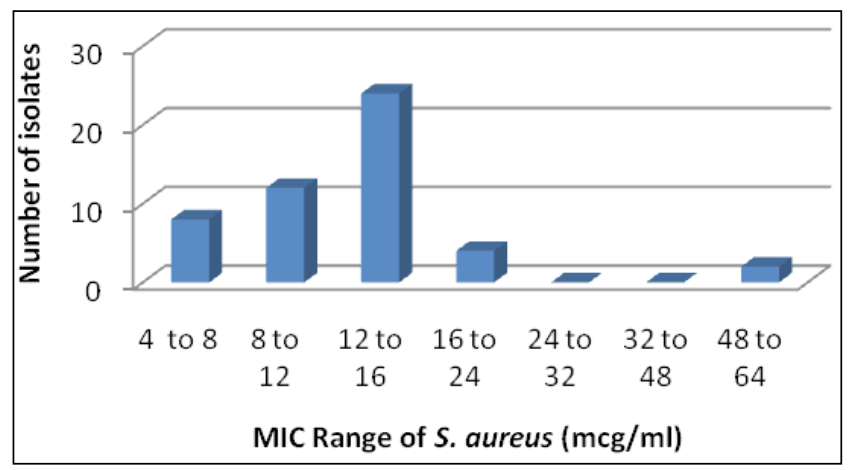

Fig. 7: MIC Range of S. aureus (mcg/ml) Vs number of isolate
Multi Drug Resistance was found in 100 percent of isolates $S$. aureus which indicate indiscriminate use of antimicrobial agents and poor manage mental practices. Multiple drug resistance has emerged among bacterial infection in last few years. There are large numbers of cases from different parts of the world that describe increased trend of developing multiple resistance strains (Rinsky et al., 2013). Yadav et al. (2017) had also reported 100percent multi drug resistance in this region. Among the $140 \mathrm{~S}$. aureus isolated from mastitic milk, 27 isolates (19.28 percent) showed resistance against 2 antibiotics, 20 (14.28 percent) isolates were resistance to 3 antibiotics, 33 isolates ( 23.58 percent) were resistant to 4 antibiotics. 40 (28.57 percent) isolates were found resistant against 5 antibiotics. 7 ( 5 percent) isolates each were resistant to 6 and 7 antibiotics. 6 isolates (4.28 percent) were resistant to 8 antibiotics.

Ankur et al. (2011) also reported 23.52 percent isolates to be resistance to 2 antibiotics, 19.11 percent isolates to be resistance to 3 antibiotics, 2 isolates to be resistance to 4 antibiotics, 1 isolates to be resistance to 5 antibiotics among 36 isolates. The multiple drug resistance in Staphylococcal was also reported by other workers (Elango et al., 2010). In the recent past, it was very strongly suggested that the indiscriminate use of antibiotic must be avoided and for clinical treatment, a proper analysis of antibiotic profile of the bacteria should be ascertained before using any antibiotic (Elango et al., 2010).

Among S. aureus, Methicillin-Resistant Strains (MRSA) has recently emerged as a serious life threatening infective agent which does not respond to a lot of antimicrobial treatments (Kamal et al., 2013). The causes of antibiotic resistance is explained by several authors and reported numerous mechanisms of conferring resistance such as antibiotic-resistant genes, mutation, clonal evolution and plasmid transfer, target site alteration of ribosome, metabolic pathway alteration, efflux pumps and enzymatic cleavage of antibiotics.

The Methicillin resistance has emerged as an important genetic trade in the $S$. aureus which is causing many complications in clinical management of infections caused by $S$. aureus. The reports on MRSA have been given by many scientists from the various parts of India. (Germa et al., 2015). Tissue invading organisms, such as coagulasepositive Staphylococci, become walled off in the udder 
parenchyma by thick fibrous scar tissue, deep-seated abscesses or gain a refuge within the acid phagolysosome of macrophages and neutrophils. Therefore, antimicrobials cannot reach the MCO and failure may occur even when the organisms are sensitive to the antimicrobial used. This may be partly due to the $\mathrm{pH}$ of the phagolysosome being around $\mathrm{pH}=4$ leading to low metabolic activity of the MCO preventing the drug from being fully effective. In other words, penetrability of the mammary gland by an antimicrobial becomes essential for evaluation of the potential therapeutic value of any intramammary preparation. Antimicrobials may penetrate these cells poorly and even when they gain access to the cell, may not distribute into phagolysosome (Du Preez 2000; Sol et al., 2000; Erskine et al., 2003). In chronic S. aureus mastitis cases, development of localized scar tissue which does not have blood vessels is promoted, meaning that intramuscular and intravenous injections probably provide little benefit and pose difficult therapeutic problems (Du Preez 1988; Du Preez 2000; Erskine et al., 2003). Therapy may kill the organisms that are not walled off, but at a later date, the organisms within the scar tissue can break out, multiply, cause additional damage to the udder secretary tissue and promote further formation of scar tissue. When antimicrobial treatment is administered, such MCOs may not come into contact with the drug and are therefore not killed (Du Preez 1988, Sandholm et al., 1990; Erskine et al., 2003). Selecting the wrong and ineffective antimicrobial agent, such as penicillin to treat $\beta$-lactamase-producing $S$. aureus or Bacteroides fragilis (Du Preez 1988; Sandholm et al., 1990; Erskine et al., 2003) can results in treatment failure.

The present study suggests antibacterial activity of Emblica officinalis against Methicillin sensitive and Methicillin resistant Staphylococcus aureus, a major step in use of E.O. as a potent phyto-therapeutic agent in treatment of mastitis. The zone of inhibition was in decreasing order as Oxytetracycline $(13 \mathrm{~mm})$ followed by Methicillin $(11 \mathrm{~mm})$, E.O.-200 (11 mm), EO-175 (10mm) Erythromycin (10mm) and Ampicillin (resistant).

In Methicillin resistant $S$. aureus isolates, the zone of inhibition was in the order Oxytetracycline followed by EO-200, Methicillin and Ampicillin, Gentamicin, Ofloxacin were resistant suggesting efficacy of $E$. officinalis even when multidrug resistance occurs. Ayurveda, which is the oldest health system in the world, appreciates and uses E.O. to treat a host of diseases and promote positive health. The active ingredient that has significant pharmacological action in this is designated by Indian scientist as "Phyllemblin". The fruit is rich in quercetin, phyllaemblic compounds, gallic acid, tannins, flavonoids, pectin, and vitamin $\mathrm{C}$ and also contains various polyphenolic compounds. A wide range of phytochemical components including terpenoids, alkaloids, flavonoids, and tannins have been shown to posses' useful biological (Kim et al., 2005; Arora et al., 2003).

Emblica officinalis is known to possess potent antibacterial activity against Staphylococcus aureus (Reghu and Ravindra, 2010; Dhale and Mogle, 2011; Patil et al., 2012; Varghese et al., 2013), Escherichia coli, Klebsiella pneumoniae, K. ozaenae, Proteus mirabilis, Pseudomonas aeruginosa, Salmonella typhi, S. paratyphi A, S. paratyphi B and Serratia marcescens (Saeed and Tariq, 2007). Emblica is an excellent antioxidant and free radical scavenger (Bhattacharya et al., 2002; Anila and Vijayalakshmi, 2003). Vitamin C in Emblica officinalis accounts for approximately 45-70percent of the antioxidant activity (Scartezzini et al., 2006). Apart from traditional uses, there are several reports in the pharmacological actions of E.O. based on modern scientific investigations, especially antiinflammatory action (Madhuri et al., 2011). Antimicrobial action (Rajeshkumar et al., 2001), anti-oxidant action (Akhtar et al., 2011) anti-ulcerogenic action (Anil et al., 2012) anti-diabetic action (Vaidya, 2006), analgesic action (Ghosh, 2008), and hepato protective action (Shymala, 2003).

The potential biological properties of Emblica officinalis remain untrapped in the animal health sector. The complete package of antibacterial, anti oxidant, anti inflammatory, free radical scavenging, hepato-protective properties in one wonder drug can thus be of immense use in the prevention and treatment of innumerable health disorders, mastitis being one of them.

The varied literature on the medicinal plant reveals that the plant E.O. have the antibacterial (Hossain, et al., 2012; Philip et al., 2012), antifungal (Hossain et al., 2012, Mehmood et al., 1999) and antioxidant properties (Golechha et al., 2012). The potent anti inflammatory activity of Emblica officinalis was earlier established by (Golechha and Mahaveer, 2014; Yokozawa, 2007; Kumar et al., 2013). Reghu and Ravindra (2010) had revealed 
the inhibitory activity of E.O. extracts to the growth of $S$. aureus. Saeed and Tariq (2007) also observed potent antibacterial activity of aqueous infusion and decoction of Emblica officinalis against Escherichia coli, Klebsiella pneumoniae, K. ozaenae, Proteus mirabilis, Pseudomonas aeruginosa, Salmonella typhi, S. paratyphi A, S. paratyphi B and Serratia marcescens. Varghese et al. (2013) also observed maximal antibacterial activity against $S$. aureus for the fruit extract, comparable with that of the commonly used antibiotics having varied mode of action and were of the view that none of the antibiotics were superior to the Emblica officinalis extracts against Pseudomonas. The bactericidal activity of $E$. officinalis could be attributed to the bioactive compounds present in E. officinalis namely flavonoids, phenols, saponins, and tannins such as emblicanin A and B which could be effectively employed as effective chemotherapeutic agents in antibacterial treatment and therapy (Javale and Sabnis, 2010; Jyothi and Rao, 2011).

The antioxidant activity of fruits of E. officinalis has been traced to its tannoid principles both in vitro and in vivo (Bhattacharya et al., 2002). The potent antioxidant properties of E.O. have also been confirmed by Hazara (2010). Vitamin C in Emblica officinalis accounts for approximately 45-70 percent of the antioxidant activity (Scartezzini et al., 2006). Chawla and Kaur (2004) showed that the elevated content of antioxidants in the blood of cows to a considerable degree protected them from metabolic diseases, including mastitis. Although ruminants can synthesize vitamin $\mathrm{C}$ in the liver and it is not considered to be an essential nutrient for healthy cattle, a large reduction in plasma vitamin $\mathrm{C}$ concentration was reported in lactating cow with artificially induced mastitis (Weiss et al., 2004). Khopde et al. (2001) reported that ascorbic acid and other polyphenols present in the natural formulation of E.O. showed much superior antioxidant activity compared to their equivalent amounts in pure isolated form.

Thus Emblica officinalis can be potentially incorporated in feeding schedule of lactating cattle to reduce the incidence of disease especially mastitis through improving nonspecific immunity of periparturient cows especially in areas where Emblica officinalis is in abundance, but it require further studies on standardization, formulation and mode of delivery to explore more beneficial effects. Plant products such as $A$. indica could be used as an anti- inflammatory and antibacterial arsenal against the disease to reduce the burden of antibiotics. This is a preliminary trial indicating the beneficial effect of the herb against intra mammary infusion; it can be developed as an alternative therapy where the use of antibiotics is normally not recommended.

Phytobiotics, herbal plant bioactive compounds, have been used in human and veterinary medicine to prevent diseases, enhance performance in stress-related syndromes, and increase resistance against infections (Rochfort et al., 2008). Phytobiotics are largely used in ruminant nutrition due to their antimicrobial (Khiaosa-ard and Zebeli, 2013) and strong antioxidant and anti-inflammatory activities. It has been demonstrated that synergism between phytobiotics in herbal plants are mainly responsible for their potent health-enhancing properties. Therefore, combinations of antioxidants with possible synergism are preferred for preventing free-radical-induced disorders. New evidence suggests that phytobiotics supplementation may be more efficient in animals that are under physiologic or environmental stress conditions (Gobert et al., 2009).

\section{CONCLUSION}

Total of 200 buffaloes were screened for sub clinical mastitis using white side test, California mastitis test and somatic cell count, out of which 115 (57.5 percent) animal were positive for sub clinical mastitis which were further subjected to cultural examination for detection of $S$. aureus. Out of 115 samples, 102 samples (88.70 percent) were found positive for $S$. aureus. Antibiotic sensitivity test was performed to sensitivity and resistant pattern of different antibiotics. As maximum sensitivity was recorded against Oxytetracyclin antibiotic disc, it was taken as standard disc to compare the in-vitro efficacy of disc prepared from ethanolic extract of E.O. at $175 \mathrm{mg} / \mathrm{ml}$ DMSO and $200 \mathrm{mg} / \mathrm{ml}$ DMSO concentration. The zone of inhibition was in decreasing order as Oxytetracyclin $(13 \mathrm{~mm})$ followed by Methicillin (11mm), E.O.-200 (11 mm), EO-175 (10 mm), Eythromycin $(10 \mathrm{~mm})$, and Ampicillin (resistant). The results indicate that the sensitivity pattern for E.O. at $200 \mathrm{mg} / \mathrm{ml}$ and $175 \mathrm{mg} / \mathrm{ml}$ DMSO concentration was comparable with those standard antibiotics in Methicillin sensitive $S$. aureus. In Methicillin resistant $S$. aureus isolates, the zone of inhibition was in the order Oxytetracycline followed by EO-200 (13 mm), 
and Methicillin, Ampicillin, Gentamicin, Ofloxacin, E.O50 are resistance.

\section{ACKNOWLEDGEMENTS}

Authors are highly thankful to the Dean, C. V. Sc. \& A.H. for their kind support and for providing necessary facility for conducting thesis work.

\section{REFERENCES}

Akhtar, M.S., Ramzan, A., Ali, A. and Ahmad, M. 2011. Effect of Amla fruit (Emblica officinalis) on blood glucose and lipid profile of normal subjects and type 2 diabetic patients. Int. $J$. Food Sci. Nutr., 62(6): 609-16.

Anil, U.T., Sanjay, J.S., Manisha, P.S., and Nehal, H.G. 2012. Hepatoprotective effect of poly herbal formulation against various hepatotoxic agents in rats. Pharmacognosy Res., 4(1): $50-56$.

Anila, L. and Vijayalakshmi, N.R. 2003. Antioxidant action of flavonoids from Mangifera indica and Emblica officinalis in hypercholesterolemic rats, Food Chem., 83: 569 -574.

Ankita, S., and Nimali, S. 2015. A multifarious potent herb: Plumbago zeylanica - a mini review. Int. J. Recent Sci. Res., 6: 4825-4829.

Ankur, T., Singh, V., Bhardawaj, M., Kumar, A., and Thakur, K. 2011. Isolation and antibacterial susceptibility testing of multi drug resistant Pseudomonas aeruginosa causing urinary tract infections. J. Chem. Pharm. Res., 3(4): 342-347.

Arora, S., Kaur, K. and Kaur, S. 2003. Indian medicinal plants as a reservoir of protective phytochemicals. Teratog Carcinog Mutagen., (suppl 1): 295-300.

Asrat, A.M.D. Woldeamanuel, Y. and Genene T. 2013. Identification and antimicrobial susceptibility of Staphylococcus aureus isolated from milk samples of dairy cows. African J. Microbiol. Res., 7 (27): 3501-3510.

Bauer, A.W., Kirby, W.M., Sherris, J.C. and Turck, M. 1996. Antibiotic susceptibility testing by a standardized single disc method. Am. J. Clin. Pathol., 45: 493-496.

Bhattacharya, S.K., Bhattacharya, A., Sairam, K. and Ghosal, S. 2002. Effect of bioactive tannoid principles of Emblica officinalis on ischemia-reperfusion-induced oxidative stress in rat heart. Phytomedicine, 9: 74-171.

Chandrasekaran, D., Nambil, A.P., Thirunavukkarasu, P.S., Venkatesan, P., Tirumurgaan, S., and Vairamuthu, S. 2015. Incidence of resistant mastitis in dairy cows in Tamil Nadu, India. J. Appl. Nat. Sci., 7(1): 304-308.

Chawla, R., and Kaur, H. 2004. Plasma antioxidant vitamin status of periparturient cows supplemented with alpha-tocopherol and beta-carotene. Ani. Feed Sci. and Tech., 114: 279-285.

Dhale, D.A., and Mogle, U.P. 2011. Phytochemical screening and antibacterial activity of Phyllanthus emblica (L.). Sci. Res. Repot., 1(3): 138-142.

Du Preez, J.H. 1988. Treatment of various forms of bovine mastitis with considerations of udder pathology and the pharmacokinetics of appropriate drugs: a review. South African Vet. J., 59: 7-161.

Du Preez, J.H. 2000. Bovine mastitis therapy and why it fails. $J$. South African Vet. Assoc., 71: 8-201.

Elango, A., Doraisamy, K. A., Rajarajan, G., and Kumaresan, G. 2010. Bacteriology of sub clinical mastitis and antibiogram of isolates recovered from cross bred cows. Indian J. Anim. Res., 44(4): 280-284.

Erskine, R.J., Wagner S. and DeGraves F.J. 2003. Mastitis therapy and pharmacology. Vet. Clinics of North Am., Food Animal Practice, 19: 109-381.

Gobert, M., Martin, B., Ferlay, A., Chilliard, Y., Graulet, B., Pradel, P., Bauchart, D., and Durand, D. 2009. Plant polyphenols associated with vitamin $\mathrm{E}$ can reduce plasma lipoperoxidation in dairy cows given n-3 polyunsaturated fatty acids. J. Dairy Sci., 92: 6095-6104.

Golechha, and Mahaveer, 2014. Anti-inflammatory effect of Emblica officinalis in rodent models of acute and chronic inflammation: involvement of possible mechanisms. Int. J. Inflamm., 32: 816-835.

Grema, H.A.,Geidam, Y.A.,Gadjama, G.B., Ameh, J.A. and Suleiman, A. 2015. Methicillin resistant Staphyloccus aureus (MRSA): a review. Adv. Anim. Vet. Sci., 3(2): 79-98.

Hossain, M.M., Mazumder, K., Hossen, S. Tanmy, M. M., and Rashid, T.T. 2012. In vitro studies on antibacterial and antifungal activities of Emblica officinalis. Int. J. Pharma. Sci. Res., 3: 1124-1127.

Javale P. and Sabnis S. 2010. Antimicrobial properties and phytochemical analysis of Emblica officinalis. Asian J. Exp. Biol. Sci., 5-91.

Jyothi, K.S. and Subba Rao, B. 2011. Screening of antibacterial activity of Emblica officinalis fruits. Pharma. online, 3: 848852.

Kader, M.A., Samad, M.A., Saha, S. and Taleb, M.A. 2002. Prevalence and Etiology of Sub-Clinical Mastitis with Antibiotic Sensitivity to Isolated Organisms among Milch Cows in Bangladesh. Indian J. Dairy Sci., 55: 218-223.

Kamal, Rania M., Mohamed, A., Bayoumi, Salah F.A. and Abd, E.I. 2013. MRSA detection in raw milk, some dairy products and hands of dairy workers in Egypt, a mini-survey. Food Control, 133(1): 49-53.

Khiaosa-Ard, R. and Zebeli, Q. 2013. "Meta-analysis of the effects of essential oils and their bioactive compounds on 
rumen fermentation characteristics and feed efficiency in ruminants. J. Anim. Sci., 91(4): 1819-1830.

Khopde, S.M., Priyadarsini, K.I., Mohan, H., Gawandi, V.B., Satav, J.G., Yakhmi, J.V., Banavaliker, M.M., Biyani, M.K. and Mittal, J.P. 2001. Characterizing the antioxidant activity of amla (Phyllanthus emblica) extract. Curr. Sci., 81(2): 185190.

Kim, H.J.,Yokozawat, K., Tohda, C., Rao, T.P. and Juneja, L.R. 2005. Influence of Amla (Emblica officinalis) on hypercholesterolemia and lipid peroxidation in cholesterolfed rats. J. Nutr. Sci. Vitaminol., 51: 413-418.

Lassa, H. and Smulski, S. 2013. Yeast like fungi as etiological agents of mastitis in cows. Zycie Weterynaryjne, 88(11): 954956.

Lowy, F.D. 2003. Antimicrobial resistance: the example of Staphylococcus aureus. J. Clin. Invest., 111(9): 1265-1273.

Madhuri, S., Pandey, G. and Verma, K.S. 2011. Antioxidant, Immunomodulatory and Anti cnacer activities of Emblica Officinalis: An overview. Int. Res. J. Pharmacy, 2(8): 38-42.

Patil, S.G., Deshmukh, A.A., Padol, A.R. and Kale, D.B. 2012. In vitro antimicrobial activity of Emblica officinalis fruit by tube dilution method. Int. J. Toxicol. Appl. Pharmacol., 2(4): 49-51.

Philip, J., John, S. and Iyer, P. 2012. Antimicrobial Activity of Aloevera barbedensis, Daucus carota, Emblica officinalis, Honey and Punica granatum and formulation of a health drink and salad, Malays. J. Microbiol., 8: 141-147.

Prachi, J. and Shilpa, S. 2010 Antimicrobial properties and phytochemical analysis of Emblica officinalis. Asian J. Exp. Biol. Sci., 1(1):91-95.

Rajeshkumar, N.V., Therese, M. and Kuttan, R. 2001. Emblica officinalis Fruits Afford Protection against Experimental Gastric Ulcers in Rats. Therm. Biol., 39(5): 375-80.

Reghu, H.S. and Ravindra, P. 2010. Antimicrobial activity and phytochemical study of Phyllanthus emblica Linn. Int. J. Pharm. Studies Res., 1(1): 30-33.

Rinsky, JL., Nadimpalli, M., Wing, S., Hall, D., Baron, D. and Price, L.B. 2013. Livestock-Associated Methicillin and Multidrug Resistant Staphylococcus aureus is Present among Industrial, Not Antibiotic-Free Livestock Operation Workers in North Carolina. PLOS One, 8(7): e67641.

Rochfort, S., Parker, A.J. and Dunshea, F.R. 2008. Plant bioactives for ruminant health and productivity. Phytochemistry, 69: 299-322.

Saeed, S. and Tariq, P. 2007. Antibacterial activities of Emblica officinalis and Coriandrum sativum against gram negative urinary pathogens. Pak. J. Pharm. Sci., 20(1): 32-35.
Samie, A., Green, E., Obi, C.L., Bessong, P.O. and Ndip, R.N. 2001. Inhibitory properties of selected South African medicinal plants against Mycobacterium tuberculosis. J. Ethnopharmacology, 130(1): 151-157.

Sandholm, M., Kaartinen, L. and Pyorala, S. 1990. Bovine mastitis--why does antibiotic therapy not always work: An overview. J. Vet. Pharmacol Ther., 1: 60- 248.

Santoshkumar, J., Manjunath, S. and Pranavkumar, M.S. 2013. A study of anti-hyperlipidemia, hypolipedimic and antiatherogenic activity of fruit of Emblica officinalis (amla) in high fat fed Albino Rats. Int. J. Medical Res. and Health Sci., 2(1): 70-77.

Scartezzini, P., F. Antognoni, M.A. Raggi, F. Poli and Sabbioni. 2006. Vitamin C content and antioxidant activity of the fruit and of the Ayurvedic preparation of Emblica officinalis. $J$. Ethnopharmacol., 104(12): 8-113.

Shymala, M.P., Venukumar, M.R. and Lata, M.S. 2003. Antioxidant potential of the Syzygium aromaticum (Gaertn) Linn (Clove) in rats fed with high fat diet. Indian $J$. Pharmacology, 35: 99-103.

Sol, J., Sampimon, O.C., Barkema, H.W. and Schukken, Y.H. 2000. Factors associated with cure after therapy of clinical mastitis caused by Staphylococcus aureus. J. Dairy Sci., 83: 84-278.

Talan, D.A., Staatz, D., Staatz, A., Goldstein, E.J.C., Singer, K. and Ocrturf, G.D. 1989. Staphylococcus intermidius in canine gingival and canine infected human wound infections: Laboratory characterization of newly recognized zoonotic pathogen. J. Clin. Microbiol., 27: 78-81.

Vaidya, A.D.B. 2006. Reverse pharmacological correlates of Ayurvedic drug actions. Indian J. Pharmacol., 38(5): 311-15.

Varghese L.S., Alex N., Ninan M.A., Soman S. and Jacob S. 2013. Evaluation of in vitro antibacterial activity whole plant (fruits, seeds, stem, leaves and roots) of Emblica Officinalis Gaertn. Int. J. Ayurvedic \& Herbal Medicine, 3(6): 14201425.

Weiss, W.P., Hogan, J.S. and Smith, K.L. 2004. Changes in vitamin $\mathrm{C}$ concentrations in plasma and milk from dairy cows after an intramammary infusion of Escherichia coli. J. Dairy Sci., 87: 32-37

Yadav, N., Fitzpatrick, E. A., You, D., Shrestha, B., Siefker, D., Patel, V.S. and Cormier, S.A. 2017. A neonatal murine model of MRSA pneumonia. PloS one, 12(1): e0169273.

Yokozawa, T., Kim, H.Y., Kim, H.J., Tanaka, T., Sugino, H., Okubo, T., Chu, D. and Juneja, L.R. 2007. Amla (Emblica officinalis) Attenuates Age- Related Renal Dysfunction by Oxidative Stress, J. Agri. and Food Chemistry, 55: 52-7744. 
